\title{
Information and communication technologies and patient empowerment: A complex skein
}

\author{
Alberto Ardissone \\ Department of Sociology and Business Law, University of Macerata, Italy. \\ Received 10 January, Accepted 19 February, 2020
}

\begin{abstract}
This article aims to explore the relationship between patient empowerment and information and communication technologies (ICTs). Indeed, ICTs are considered important for increasing access to medical information and for patients' other experiences, thereby nourishing the empowering rhetoric. The paper presents a research study conducted in Italy that focuses on the self-assessments made by online health communities (OHCs) users, subdivided in three categories, according to their level of online activity: Lurkers, occasionally active users and frequently active users. The concept of empowerment was operationalised in five issues: autonomy from doctors, involvement in medical decision-making, competence, self-management and acceptance. The results support the relationship between perceptions of empowerment and the higher level of activity played on OHCs, contributing instead to reject the idea of a generalised benefit. Moreover, the paper aims to enrich the theory of patient empowerment by adding a socio-material perspective. This helps broaden the understanding of the relationship between empowerment and ICTs by highlighting its underlying complex skein.
\end{abstract}

Key words: Empowerment, self-management, information and communication technologies, online health communities, socio-material perspective, chronic disease.

\section{INTRODUCTION}

This article explores the relationship between empowerment, chronic diseases and information and communication technologies (ICTs) by presenting the main results of a research study conducted in Italy in 2017. The purpose of this study was to assess how people with chronic diseases perceived themselves to be empowered by using some ICTs, and how potentially different perceptions can be explained.

Indeed, patient empowerment or patient engagement, whose terms are often used interchangeably, have become a 'hallmark of digital health rhetoric' (Lupton and
Jutel, 2015: 132), and an ideal to be pursued in contemporary healthcare (Andreassen and Trondsen, 2010; Akeel and Mundy, 2019), as well as for aims related to the economic sustainability of the system (De Luca et al., 2019). This rhetoric is spurred on by a seemingly endlessly upcoming revolution in healthcare driven by the newest digital technologies (Lupton, 2013). The relentless progress of digitalization has provided a manifold array of devices and software. In particular, due to the advancement from Web 1.0 to Web 2.0, ICTs directly supply all citizens with relevant channels, which

E-mail: ardi76@gmail.com.

Author(s) agree that this article remain permanently open access under the terms of the Creative Commons Attribution License 4.0 International License 
have exponentially expanded access to medical and health information, as well as to other patients' experiences. Consequently, 'the Web 2.0 era has heralded new ways of encouraging patients to be more engaged in healthcare' (Lupton, 2013: 259). Therefore, between technology, generally speaking, an empowerment has emerged such a strong nexus that makes it almost impossible to conceive the latter without the former (Akeel and Mundy, 2019).

This article is organised as follows: the first section addresses the concept of patient empowerment; the second section outlines the specific ICTs included in this study and their alleged empowering potential; it also presents a brief discussion of the opposing stances concerning the relationship between empowerment and technologies; the third section will introduce methodology and design of the study; the final sections present and discuss the main results of the research and draw conclusions.

\section{RELATED WORK}

\section{The patient empowerment paradigm and its operationalisation}

Usually, scholars use the term patient empowerment, 'despite the fact that persons who are not at the moment patients are also included' (Shultz and Nakamoto, 2013: 5). It describes the participation of patients as autonomous actors, accountable for their own health and care, and with a more active role in their clinical decision making (Shultz and Nakamoto, 2013). Its ultimate aim is for patients to achieve their well-being, intended as their physical and psychological health (Ippolito et al., 2019). The main attributes are the following (Castro et al., 2016): an enabling process, which, for instance, supports selfmanagement interventions; achieving a personal change; self-determination, which is described as the right and ability to make one's own choices.

The lack of a conceptual consensus (Akeel and Mundy, 2019; Barr et al., 2015; Daruwalla et al., 2019) and the limited research on psychological-patient empowerment (Shultz and Nakamoto, 2013) reflect on the absence of consistent operationalization. Consequently, at the moment there is still 'no universally accepted generic measurement instrument for patient empowerment' (Castro et al., 2016: 1927). Most existing scales focus on specific issues, such as particular diseases or specialties, and have significant shortcomings, above all with respect to reliability and responsiveness (Barr et al., 2015). To overcome this problem, Shultz and Nakamoto (2013) proposed four constructs: (a) meaningfulness, which expresses the feeling that what one does is meaningful and worth investing energy in; (b) self-efficacy (or competence), representing the belief and the confidence patients have in their ability to manage their own health; (c) impact, which embodies the perception about the relevance of accomplishing a task; (d) self-determination, as autonomous decisions that patients take on their own. Besides, even though empowerment is a distinct concept from health literacy, they are 'closely interwoven' and then must be considered in conjunction (Shultz and Nakamoto, 2013). In addition, by conceiving patient empowerment as that process and outcome of mastery over one's life and health management, we ought to consider that it might take 'different forms for chronic and acute conditions'; consequently 'different forms may require different measures' (Shultz and Nakamoto, 2013: 9).

Stemming from this statement, and considering that the target of this paper are people living with chronic diseases and conditions, we propose an operationalisation of patient empowerment that in part differs from the past studies discussed above. To begin with, we recognised the importance of accounting for different features of a chronic malady, namely its objective and subjective aspects. Recalling Twaddle (1968), by disease we mean the objective, examinable and observable form of malady, whose basic phenomena are physiological, biochemical, genetic, and mental entities and events; while, for illness, we mean its subjective part, characterised by emotions and experience, as well as status, such as anxiety, fear or pain. Then, we propose operationalisation by detecting five elements intertwined between themselves:

(i) Competence: Rather than considering it as a synonym of self-efficacy, as per above, we inflected competence as the knowledge and awareness of the patient about his/her disease. It is basically what one knows about one's pathology, which, for instance, allows the person to identify symptoms and to understand the contents and procedures of diagnosis and medical treatments. It is the theory about the objective aspects of the malady. With this term we intended to include the concept of health literacy in our operationalization.

(ii) Self-management: It was described as the most important element of self-care for all people with chronic conditions (Rijken et al., 2008): indeed, in the field of chronic disease above all, people need to have an active role in the management of many aspects of their health, including psychological, physical and social ones (Kondylakis, 2020). For instance, people with diabetes are estimated to manage $95 \%$ of their condition on their own (Almanea et al., 2019). Self-management is such a relevant concept that sometimes it is even used interchangeably with the term of patient empowerment (Castro et al., 2016); it is also described as one of the most frequent consequences associated with patient empowerment itself. It implies the development of important skills which refers to those activities undertaken daily directly by the person with a chronic condition, such 
as managing symptoms, treatment, physical and psychosocial issues and making lifestyle changes (Castro et al., 2016; Ippolito et al., 2019; Rijken et al., 2008).

(iii) Acceptance: It is described as the end point of the five-stage process elaborated by Kübler-Ross (1969). With acceptance we aim to include subjective and emotional spheres in in empowerment construction or illness in Twaddle's terms. Indeed, people with chronic conditions experience the emotional status connected with such illnesses. It has been shown that a pathology entails the need to cope with their threatened sense of security and identity, and to reframe and to reinterpret their illness and new lifelong condition (Castro et al., 2016). The need to assign a meaning to the changes inherent to a chronic condition is related to a renewed sense of equilibrium, and it can sustain personal vitality, competence and power (Aujoulat et al., 2008). Thus, the importance of acceptance in the empowerment construct for people with chronic condition is paramount.

(iv) Involvement in clinical and therapeutic decisionmaking; as Roberts (1999: 86) put it: 'once empowered, patients engage in more egalitarian-type relationships with their physicians'. Hence, empowerment allows for a redistribution of power between physicians and patients, by which the latter increase their role and control during their encounters with doctors (van Uden-Kraan et al., 2008) and get the ability of having 'a voice at the table' (Daruwalla et al., 2019, 70), by participating in decisionmaking about their own care as active agents (O'Chatain et al., 2005). Indeed, participation is considered paramount to allowing patients to achieve a sense of purpose (Agner and Braun, 2018). Therefore, the ability to participate in the clinical-therapeutic decision-making process is a relevant part of the concept of empowerment (Akeel and Mundy, 2019; Ippolito et al., 2019).

(v) Autonomy from doctors: It is the way in which we defined the concept of self-determination, recalling that 'autonomy has been defined as self-government or selfdetermination' (Wray, 2004, 23). Described as the right and ability to make one's own choices, self-determination is a guiding principle of empowerment-based interventions. This, in turn, implies that 'patients are selfdetermining agents who have the ability for autonomy' (Castro et al., 2016, 1927). Therefore, notions of autonomy and independence are closely linked to agency and empowerment (Daruwalla et al., 2019).

In this way, we can operationalise the concept of patient empowerment having people with chronic diseases as a target, and by keeping together the microlevel elements of personal aspects of disease and illness (competence-knowledge and acceptation), practical individual skills (self-management), and the relational processes/outcomes with doctors (autonomy and involvement).

\section{The spread of ICTs and their empowering potential}

As Akeel and Mundy $(2019,1280)$ put it, 'technology is by far the most prominent tool concerning the development of an approach to patient empowerment'. More specifically, knowledge and medical information online are considered very important for patient empowerment as they are particularly suitable to contributing to its process (Lupton and Jutel, 2015; Roberts, 1999; Swan, 2009). This suggests that empowerment can be achieved by using some digital technologies that permit selfmonitoring, self-management and self-care (Lupton, 2013; Petrakaki et al., 2018).

In this study, we focused our attention on three ICTs, which are increasingly available to lay people and correspond to this purpose (Karni et al., 2019): the internet, with websites addressing health and medical information; the online health communities (OHCs) existing on the social network sites platforms; and medical and health apps. Many scholars have highlighted the role of the internet in increasing the dissemination and the availability of health and medical information (Amante et al., 2015; Anshari, 2019; Tonsaker et al., 2014). The internet has even become the main channel used by lay people looking for such information (Amante et al., 2015; Tan and Goonawardene, 2017). Consequently, it has helped change the way in which people get information about their health and illness (Ybarra and Suman, 2008), whose related processes no longer depend only on health professionals (Tan and Goonawardene, 2017; Tomeny et al., 2017).

The progress towards Web 2.0 has fostered the birth and the massive diffusion of OHCs (Willis and Royne, 2017); these communities have rapidly become frequented by an important segment of Web users (Willis, 2016). OHCs 'consist of an internet-based platform that unites groups of individuals with a shared goal or similar interest' (van der Eijk et al., 2013), as well as similar health/disease conditions (Willis, 2016). One of their main characteristics is to permit a connection among people 'who would otherwise never have met' (van der Eijk et al., 2013), facilitating 'a sense of connectedness' which in some cases would be more difficult to attain in offline environments (Dickins et al., 2016). Hence, OHCs help overcome problems such as: geographical distances; or a sense of loneliness due to the small numbers of people suffering from a specific disease (rare diseases); or other aspects of the disease related to societal matters (e.g., social stigma). OHCs are mainly peer-to-peer channels (Pempek et al., 2009, 236), featuring a horizontal culture (Tomeny et al., 2017): this potentially allows for a broadbased discussion among all members for each post, making it difficult to detect the most hierarchically reliable answer.

Health and medical apps have grown greatly in number since 2008, reaching the figure of almost 325,000 apps (Akbar et al., 2020). These mobile software applications 
represent the newest development of the process of digitalization of health and medical information (Lupton, 2014b). They address several needs (Akbar et al., 2020; Lupton, 2014b): from information delivery on medical conditions and treatments, to apps with sophisticated algorithms in order to assist users with self-diagnosis, or self-care and self-management activities; others can monitor and measure many bodily parameters, in conjunction with wearable devices, and can help people in self-tracking activities. Besides, some are particularly designed for professionals while others for lay people who can, in any case, access both of them.

The debate about the pros and cons related to these ICTs is quite polarised in the current literature. Basically, we have a well-established dichotomy between technocritics and techno-optimists (Lupton, 2014a), which in turn reflects the juxtaposition of nightmares and promises embedded in the technologies (Pols, 2012). Thus, on the one hand, we find scholars who highlight the empowering processes allowed by ICTs. Accordingly, by offering online emotional support (Foster, 2016), as well as clinical knowledge emerging 'from engaging with likeothers' (Willis and Royne, 2017, 269), they permit a 'novel form of health expertise' (Foster, 2016: 26); this fosters the figure of 'experts by experience', whose lay knowledge tends to become developed in a collective nature via people's lived experience and mostly by means of social media (Maslen and Lupton, 2019). OHCs, in particular, have been identified as a key factor for living with a long-term condition, for facilitating personal self-management (Fergie et al., 2016) and for contributing, through all the information and support received, to users' empowerment (Almanea et al, 2019). These online peer-to-peer groups are sometimes used more than medical consultation to support therapeutic treatment (Centola and van de Rijt, 2015; Topol, 2015). Also apps, in conjunction with wearable devices, foster people empowerment: by allowing quantified-self practices, individual bodies are made 'knowable, calculable, and administrable objects' and this helps achieve 'the most vaunted of human commodities: choice, understanding, consciousness, and freedom' (Swan, 2013: 96).

On the other hand, many scholars contrast this 'tecnoeuphoria' (Lupton, 2015) by highlighting the possible distorting effects produced by technology. Among the social, cultural and economic aspects related to the adoption and use of technologies, which lead these scholars to reject the idea of empowerment, we find: (a) the commodification of personal data, involving data security and their possible commercialization (Lupton, 2015); (b) the increasing surveillance through those technologies, which disempower people, because they are used to 'disciplining and managing populations via an extension of the medical or "panoptic" gaze' (Sharon, 2017: 98); (c) the practice of dataveillance, that was described as a form of continuous surveillance that takes place through the use of meta-data, which are unremittingly tracked for unstated predetermined purposes (Lupton and Michael, 2017; van Dijck, 2014); (d) the overstatement of empowerment as a consequence of people's use of online information, which underestimates, for instance, the different levels of resources they may have to act upon that information (Koteyko et al., 2015).

Another important dispute concerns the benefits derived from the $\mathrm{OHCs}$ in particular. Individuals can be influenced by the posts they read, regardless of the kind of activity performed on such platforms (Syn and Kim, 2013; Verduyn et al., 2017). However, the question is open when assessing the achievement of the benefits according to the activity that took place. On one hand, these platforms were also found to be useful for passive users because of the sense of closeness OHCs provide and the suggestions people can receive (Erfani et al., 2016). On the other hand, studies have highlighted the need for users to be active in order to gain more benefits (Bliuc et al., 2017): in particular, negative consequences may raise when users have passive habits on online platforms, increasing the risk for eating disorders (Saffran et al., 2016), anxiety, envy and frustration (Verduyn et al., 2017).

\section{Theoretical background}

Given this controversial background, the purpose of this article is to contribute to the debate on the benefits offered by such technologies. We asked people with chronic diseases and conditions, who frequented $\mathrm{OHCs}$, to report their evaluations, in order to appraise the degree of empowerment they perceived having achieved by means of ICTs. The study also considered the level of people's online engagement to verify possible differences in the self-perception of benefits. To our knowledge, so far no other studies have been conducted in Italy with this precise purpose.

Past studies proposed different ideal types of online users. Basically, we can have active users and passive users (de la Peña and Quintanilla, 2015), or, in other terms, posters and lurkers (van Uden-Kraan et al., 2008). While the former post and comment in the community, the latter simply read what has been written by the other members. Usually, lurkers represent the 'normal online behaviour' (O'Neill et al., 2014), the silent majority. Other scholars have further refined this taxonomy either on the basis of user-generated-content (O'Neill et al., 2014) or by linking engagement online with support enjoyed offline (Fergie et al., 2016).

In this research, we proposed three ideal types of $\mathrm{OHC}$ users, based on the kind of activity performed consistently with the purpose of this study: lurkers, the passive readers; occasionally active users, people who join online debates in the community, commenting or 
giving suggestions, only infrequently; and, frequently active users, people who usually intervene in online communities by posting, commenting on other posts, questioning, answering and so on.

Based on the discordant literature on empowerment, reviewed above, and presuming that ICTs may actually increase the level of patients' empowerment, we expect to see that the more one is engaged in online activities, the more one will perceive being empowered by means of ICTs and will assess their relevance as sources for their empowerment. Furthermore, we expect to see three groups that are clearly different from each other, according to the status of frequently active users, or occasionally active users, or lurkers.

However, we do not think that possible differences in self-perceptions and assessments will only depend on different levels of online engagement. This might account for part of the explanation. The socio-material perspective may help to shed light on the picture. Indeed, through these approaches technologies are described in terms of socio-cultural artefacts, whose core are actually socially built (Koteyko et al., 2015), as a co-production of science and society (Geelen et al., 2016). Hence, humans and technologies/non-humans form a wide array of interactions, combinations or 'assemblages' (Lupton, 2014b), which gives rise to different perspectives, interpretations and understandings according to the different social groups and individuals. This is at the basis of the processes of 'unleashing and taming', which can eventually lead to either a domestication or to resistance or to rejection of specific technologies (Pols, 2012). From this perspective, human actors are active users, forming together a circular loop in which co-adaptation, identities, values, norms, and so on, are continually built and rebuilt. This theoretical framework may help interpret why people use ICTs in different ways, going beyond other problems already faced, such as the digital divide or internet penetration rates; we wanted, rather, to focus on people's possible different purposes and relationships with ICTs as another possible explanation to add to the former ones.

\section{RESEARCH DESIGN}

The research was conducted in Italy and was based on a web survey delivered through Facebook's OHCs. With almost 2.5 billion users, Facebook is currently the most widely used social networking site worldwide (Statista, 2020), and one of the most important in this field as it has many health communities (see also Maslen and Lupton, 2019). We reached 190 Italian OHCs, mainly single issue, as the research was geographically limited just to Italy. After administrators' approvals were obtained, respondents were recruited by posting messages on the 'walls' of such groups. These messages explained the focus and purpose of the research, provided the privacy rights statement and the link to access the survey. In this way, we used a sample of convenience for two basic reasons. First, sampling on Facebook is a difficult operation, and we did not have a complete list of people with chronic diseases living in Italy. Second, it helped the purpose of achieving the highest possible number of replies. It must be noted that the research aimed to understand the attitudes of Web users (with chronic diseases), not Italians as a whole.

The survey, written in Italian, was divided into five main sections which were preceded by a preliminary mandatory eligibility question: as a matter of fact, the survey only addressed people aged 18 or over and those who were living with a chronic disease. The sections were the following: the first one was intended to understand the amount and the reason for using the internet; the second one regarded the use of online health communities; the third one regarded the use of health related apps; the fourth one asked respondents about their relationship with their own doctors; and, lastly, there was a section for socio-demographic variables (e.g., age, gender, level of education, occupation, etc.). This paper analyses and discusses the results concerning the fourth section. Indeed our respondents were asked to assess on a 5-point Likert scale the relevance of four sources (the internet, OHCs, health and medical apps, and physicians) in relation to those five elements detected for operationalising empowerment: competence, selfmanagement, acceptance, autonomy from doctors, and involvement in medical decision-making.

The survey remained online for approximately four months in 2017, and 3,193 replies were received overall. Among the main features of the respondents, we can stress the following: women represented the majority (86.5\%), in line with other studies (Saffran et al., 2016) but with a bigger percentage, because some of the groups targeted only or chiefly women (e.g., because of the type of illness, such as endometriosis or fibromyalgia); the average age was 44.7 (the age range of respondents was between 18 and 85); $85.2 \%$ possessed a high educational level (high school diploma: $50.3 \%$; bachelor's degree or higher: $34.9 \%$ ); $50.8 \%$ had been diagnosed less than 10 years before.

Considering our three $\mathrm{OHC}$ profiles, we can summarize the following characteristics. Men were more frequently active users than women $(23.4 \%$ vs. $16 \%)$, and consistently women tended to lurk more than men (17.1\% vs. $12.8 \%)$, in line with other studies (O'Neill et al., 2014). Young users represented the higher percentage of lurkers and the lower percentage of frequently active users. Adults were the most active group. This can be explained not by familiarity with the technology but rather by the individual's perceived level of expertise regarding the malady in correlation to how much time has elapsed since he/she was diagnosed. Finally, the research showed that while people with higher educational attainment tended to lurk more than those with lower educational attainment, the highest percentage of frequently active users had a junior high school level of education, even though the different groups reached similar percentages (bachelor's degree or higher: 17\%; between high school and a higher education degree: $16.2 \%$; junior high school or less: $18.3 \%$ ).

\section{RESULTS AND DISCUSSION}

Overall respondents asserted that ICTs foster more involvement in therapeutic decision-making rather than more autonomy from doctors (Table 1). Thus, on one hand, ICTs promote an active approach, which fits more democratic models of doctor-patient relationship, based on therapeutic alliances or 'cooperative models' (Andreassen and Trondsen, 2010). And, on the other hand, results support the idea that empowerment seems to be more linked to satisfying relationship and involvement rather than acting autonomously (Ippolito et al., 2019).

Nevertheless, we saw an important difference in the 
Table 1. ICTs and empowerment in respondents' self-perceptions, according to OHCs level of engagement.

\begin{tabular}{|c|c|c|c|c|}
\hline & & $\begin{array}{l}\text { Frequently active } \\
\text { users (\%) }\end{array}$ & $\begin{array}{c}\text { Occasionally active } \\
\text { users (\%) }\end{array}$ & $\begin{array}{c}\text { Lurkers } \\
(\%)\end{array}$ \\
\hline \multicolumn{2}{|c|}{$\begin{array}{l}\text { ICTs help you to increase your autonomy and independence } \\
\text { from your doctors }\end{array}$} & 50.6 & 33.8 & 35.2 \\
\hline \multicolumn{2}{|c|}{$\begin{array}{l}\text { ICTs help you to increase your involvement in the therapeutic } \\
\text { decision-making }\end{array}$} & 70.9 & 57.2 & 59.6 \\
\hline \multirow{4}{*}{$\begin{array}{l}\text { Relevant } \\
\text { sources for } \\
\text { competence }\end{array}$} & Internet (health websites, etc.) & 55.7 & 47.1 & 46.8 \\
\hline & $\mathrm{OHCs}$ & 72.6 & 54.6 & 48.2 \\
\hline & Apps & 25.0 & 13.1 & 13.6 \\
\hline & Doctors & 74.2 & 76.2 & 76.5 \\
\hline \multirow{4}{*}{$\begin{array}{l}\text { Relevant } \\
\text { sources for } \\
\text { self- } \\
\text { management }\end{array}$} & Internet (health websites, etc.) & 51.0 & 41.7 & 44.0 \\
\hline & $\mathrm{OHCs}$ & 72.8 & 54.0 & 46.5 \\
\hline & Apps & 25.1 & 17.9 & 15.1 \\
\hline & Doctors & 75.2 & 77.4 & 73.7 \\
\hline \multirow{4}{*}{$\begin{array}{l}\text { Relevant } \\
\text { sources for } \\
\text { acceptance }\end{array}$} & Internet (health websites, etc.) & 78.8 & 75.1 & 75.9 \\
\hline & OHCs & 75.8 & 63.0 & 51.5 \\
\hline & Apps & 22.7 & 14.5 & 13.1 \\
\hline & Doctors & 60.8 & 61.3 & 57.0 \\
\hline
\end{tabular}

assessments of the three groups of OHCs users. People who identified themselves as frequently active users were decidedly more prone to assess ICTs as useful, both for increasing involvement and for achieving wider independence from doctors. Whereas, occasionally active users and lurkers tended to follow quite similar patterns on this topic: they were found to be very close to one another, but starkly distant from the frequently active users. More specifically, occasionally active users assessed the possible contributions of ICTs even more negatively than the lurkers; however, such differences were slight.

In the case of competence, physicians were ranked highest by each group we considered. However, focussing on the frequently active users' evaluations, we can highlight three important elements: (a) doctors and OHCs were rated very similarly; (b) the contribution of doctors was considered slightly less relevant compared with the other two groups; (c) simultaneously, all the technologies analysed received significantly more positive evaluations. Thus, when compared to other online surfers, for frequently active people with chronic diseases, doctors are still important, but they are slightly less important; whereas, all the ICTs were considered to be more important and consistently appraised more positively. Moreover, once again, lurkers and occasionally active users were found to follow almost overlapping trends in all the assessments regarding the sources. The only exception regards OHCs: in this case, occasionally active users ranked $\mathrm{OHCs}$ higher than lurkers did.
Turning to self-management, we see that the ranking of the sources does not change among the three categories of users, meaning that doctors are always the first source for each of them. Besides, even though the highest rating is given by the occasionally active users, the percentages amongst the three groups of online users are very close. Nonetheless, frequently active users evaluated all the above-mentioned ICTs more highly than did the other groups. Specifically, the differences registered among the groups concerning the relevance of OHCs and apps are of particular note. In addition, we can see that for the frequently active users, OHCs were ranked nearly as highly as physicians (72.8 and $75.2 \%$ respectively), separated by just $2.4 \%$; in contrast, for the other sub-sets of users the difference exceeded $20 \%$. Consequently, on the one hand, this makes clear that being particularly active on OHCs does not imply dismissing the value of physicians; on the other hand, it is also evident that, for these users, OHCs and doctors are both considered to be very important sources, with both ranked almost equally. This result is even more marked given the large differences between the rankings expressed by frequently active users and those of lurkers and occasionally active users. Moreover, considering that frequently active users rated $\mathrm{OHCs}$ and physicians similarly also with regard to competence (respectively 72.6 and $74.2 \%$, with a difference of $1.6 \%$ ), it seems clear that for this segment of the population doctors are not the sole source for medical information and treatments; rather, physicians and peers tend to be equally important for frequently active users. In other 
Table 2. Different patients' approaches to ICTs (Principal Component Analysis).

\begin{tabular}{|c|c|c|c|c|c|}
\hline & & \multicolumn{4}{|c|}{ Component } \\
\hline & & 1 & 2 & 3 & 4 \\
\hline \multicolumn{2}{|c|}{$\begin{array}{l}\text { ICTs help you to increase your autonomy and independence from } \\
\text { your doctors }\end{array}$} & 0.735 & 0.144 & -0.159 & -0.030 \\
\hline \multicolumn{2}{|c|}{$\begin{array}{l}\text { ICTs help you to increase your involvement in the therapeutic } \\
\text { decision-making }\end{array}$} & 0.749 & 0.017 & -0.076 & -0.006 \\
\hline \multirow{4}{*}{ Competence } & Internet (health websites 0. ecc.) & 0.698 & 0.036 & -0.078 & 0.265 \\
\hline & $\mathrm{OHCs}$ & 0.720 & 0.155 & -0.013 & 0.195 \\
\hline & Apps & 0.199 & 0.888 & -0.005 & 0.027 \\
\hline & Doctors & -0.084 & -0.065 & 0.868 & -0.033 \\
\hline \multirow{4}{*}{$\begin{array}{l}\text { Self- } \\
\text { management }\end{array}$} & Internet (health websites0. ecc.) & 0.696 & 0.105 & -0.045 & 0.315 \\
\hline & OHCs & 0.705 & 0.182 & -0.003 & 0.255 \\
\hline & Apps & 0.172 & 0.899 & -0.027 & 0.040 \\
\hline & Doctors & -0.073 & -0.033 & 0.905 & -0.012 \\
\hline \multirow{4}{*}{ Acceptance } & Internet (health websites 0. ecc.) & 0.256 & 0.132 & 0.028 & 0.864 \\
\hline & $\mathrm{OHCs}$ & 0.290 & 0.160 & 0.092 & 0.814 \\
\hline & Apps & 0.051 & 0.859 & 0.006 & 0.317 \\
\hline & Doctors & -0.094 & 0.073 & 0.797 & 0.143 \\
\hline
\end{tabular}

words, frequently active users of $\mathrm{OHCs}$ may at least supplement doctors with other sources with which these users come into greater competition, as previous studies have shown (Griffiths et al., 2012; Tan and Goonawardene, 2017).

In contrast to the previous issues, acceptance is marked by a shift in the ranking of the sources. As a matter of fact, physicians were considered to be the most important pillar both for competence and selfmanagement, cutting across all three sub-groups, albeit with the differences we identified. On the contrary, the internet was the highest-ranked source for acceptance, followed by the OHCs, whereas doctors dropped into third position. This result confirms that the profession's weak point is in addressing the social and emotional components of a malady, namely the illness with its subjective experience, in Twaddle (1968)'s terms. It is also true that the process of acceptance and of living with a chronic disease is a daily task, while encounters with doctors take place only a few days in one year, and for only a few minutes each time. Consequently, it seems understandable to seek necessary support (social, emotional, psychological) elsewhere, such as in networks of peers, thus leading people to turn to the internet and to OHCs. If anything, it is quite striking to see the internet rated better than OHCs on this issue; this is despite much of the literature affirming the specific role of $\mathrm{OHCs}$ for emotional support, sense of connectedness and for coping with long-term conditions (Dickins et al., 2016; Fergie et al., 2016; Foster, 2016). A last consideration: in any case, apps were consistently rated significantly lower than all the other sources in this research. This shows that apps still represent a niche in the field of health and healthcare, at least in Italy, even among people familiar with ICTs, and OHCs in particular.

This first part showed a partial confirmation of our hypotheses. It is true that the more one is active online, the more one perceives to be empowered by ICTs. However, the boundaries between lurkers and occasionally active users were definitely blurred. This result seems to suggest the importance of being active to feel the benefits, in line with Bliuc et al. (2017). Whereas, being occasionally active on the communities could even lead to lower self-perceptions than those experienced by the lurkers. Consequently, considering our purpose and given these findings, only two actors should be considered: frequently active users and mostly passive users.

In order to delve further into the relationship between patient empowerment and ICTs, we propose a principal component analysis (Table 2), which encompasses all the elements we detected for operationalising the concept of empowerment. The analysis enabled us to identify four different groups:

(i) The first group can be described as the pragmatic protagonists, because they are active patients both with regard to their own health and their relationships with their doctors. They pursue both autonomy and more involvement. Moreover, their use of technology is aimed 
at developing more competence in their own disease and improving their self-management.

(ii) The second group is characterised by a molecular 'technologisation'. They are particularly committed to technology and consider apps paramount for their competence, self-management and even acceptance. They do not seek a relationship with doctors; thus, it seems that they manage their disease on their own, with only the help of apps.

(iii) The third group tends to rely exclusively on doctors in any field connected to their disease. As Roberts (1999) put it, not all patients want to be involved in medical decision-making. This group, then, can be framed using more traditional patterns.

(iv) Finally, we find the emotional Web surfers. The cornerstone of their persona is the emotional level of acceptance, which is achieved through the use of the internet and $\mathrm{OHCs}$.

The results of the PCA allowed us to go beyond the issue of the level of online activities performed by patients with chronic conditions, thereby broadening our comprehension. Indeed, the PCA identified four groups who faced health/illness and ICTs in different ways: this showed how the relationship between technologies and people can be quite heterogeneous. The socio-material perspective helps to interpret this variety. As shown by previous research, patients may either use technologies or reject them, or use them in diverse or ambivalent ways (Lupton, 2013). What this PCA shows is that they can use the very same technology in different ways and for different purposes. All this, in turn, makes the snapshot of patient empowerment in relation to ICTs more complex. Indeed, we have to consider at least: (a) differentiation according to diverse online activity; (b) different perspectives stemming from the above-mentioned strategies of adaptation and refusal; (c) different possible opportunities and skills (socio-economic determinants) possessed by different groups of patients. All these elements can account for varying use (or non-use) and purposes related to ICTs, as well as for different levels, processes and achievements of empowerment.

\section{Conclusions}

This article analysed whether ICTs enhance patient empowerment. This research showed that the type of online activity is indeed strictly correlated with different self-evaluations about both the relevance of ICTs and the level of empowerment perceived. By and large, frequently active users had higher perceptions of being empowered by means of their use of ICTs, as compared to other groups. These users reported greater levels of autonomy from doctors, more involvement in medical decisionmaking, and appreciated all the technologies as being very important for their own competence, self- management and acceptance. In contrast, lurkers and occasionally active users tended to rate all the aforementioned issues lower; besides, the differences between these two groups were not so marked but were very distant from the frequently active users. In this sense, we can confirm that the more one is engaged online, the more one is empowered. However, we also detected a clear distinction in only two groups, rather than those three originally proposed: frequently active users and mostly passive users, which encompass both occasionally active users and lurkers, whose boundaries were too blurred in this research to support a distinction between them. Therefore, this result highlights that the benefits stemming from the use of $\mathrm{OHCs}$ are related to the active role employed online, in agreement with previous studies (Bliuc et al., 2017; Saffran et al., 2016; Verduyn et al., 2017); on the contrary, it contributes to rejecting the idea of a generalised benefit, which disregards the type of usage adopted. So, it is not merely a matter of how much time one spends on OHCs (quantity), but also, and perhaps above all, how one spends that time (quality), that is, if one intervenes or not, if one is active or not.

Furthermore, the research showed the existence of varied groups of people who related differently to ICTs. Among them, some relied on ICTs for pragmatic purposes, others for emotional support; some relied exclusively on doctors, others exclusively on apps for health and illness. Therefore, we found several people employing ICTs in numerous and varied ways and for numerous and varied purposes, as well as people who did not use them at all.

We interpreted all these results by using a sociomaterial perspective: this helps to assess the correlation about empowerment and different online activities, as well as the diverse and ambivalent ways in which people with chronic diseases may approach and use, or don't use, ICTs (e.g., Lupton, 2013). This means that the very same technology can be used in different ways and for different purposes by different people, even when they have the same disease. In practical terms, we ought to underline the existence of a very complex and tangled skein, which clearly downplays trivial equations between access to medical information and achievement of patient empowerment. In fact, we have to consider that those allegedly empowered by ICTs are only a small group, the frequently active users, notoriously a niche, accounting for $17 \%$ in this study and even less in others' (O'Neill et al., 2014); besides, we should also take into account other issues, such as the social determinants and thus overcome individualistic ideologies and approaches to empowerment, as suggested by Agner and Braun (2018). Furthermore, the results, in line with previous research (Ippolito et al., 2019; Jaana et al., 2019), stress that empowerment is much more linked to involvement and satisfying relationships between patients and physicians, rather than approaches based on autonomy. In other 
terms, being empowered does not mean the will of being autonomous self-acting entities, in which doctors are excluded or activated just on demand, on the basis of an individualistic approach. On the contrary, empowerment 'needs to be seen in a relational perspective' (Nielsen and Johannesses, 2019, 57), which also implies professionals' efforts to consider differences between patients, as well as the chance for people not to take a position of responsibility for their own care (Nielsen and Johannesses, 2019: 57).

In conclusion, we believe this study contributes to the enrichment of the theory of empowerment in healthcare by adding a socio-material perspective, which helps to shed light on its complexity. Such an approach should help professionals and policymakers not to take for granted neither people's adoption of ICTs, as demonstrated above by an important variability of assessments and behaviours, nor people's will to be empowered.

\section{CONFLICT OF INTERESTS}

The author has not declared any conflict of interests.

\section{REFERENCES}

Agner J, Braun KL (2018). Patient empowerment: A critique of individualism and systematic review of patient perspectives. Patient Education and Counseling 101:2054-2064.

Akbar S, Coiera E, Magrabi F (2020). Safety concerns with consumerfacing mobile health applications and their consequences: a scoping review. Journal of the American Medical Informatics Association 27(2):330-340.

Akeel AU, Mundy D (2019). Re-thinking technology and its growing role in enabling patient empowerment. Health Informatics Journal 25(4):1278-1289.

Almanea A, Bath P, Sbaffia L (2019). Online support groups as a source of empowerment for people with type 2 diabetes. In. OhnoMachado L, Séroussi B (Eds.), MEDINFO 2019: Health and Wellbeing e-Networks for All. Amsterdam, Berlin, Washington: IOS Press 264:1893-1894.

Amante DJ, Hogan TP, Pagoto SL, English TM, Lapane KL (2015). Access to care and use of the internet to search for health information: results from the US National Health interview survey. Journal of Medical Internet Research 17(4):e106.

Andreassen HK, Trondsen M (2010). The empowered patient and the sociologist. Social Theory and Health 8(3):280-287.

Anshari M (2019). Redefining Electronic Health Records (EHR) and Electronic Medical Records (EMR) to Promote Patient Empowerment. International Journal on Informatics for Development 8(1):35-39.

Aujoulat I, Marcolongo R, Bonadiman L, Deccache A (2008). Reconsidering patient empowerment in chronic illness: a critique of models of self-efficacy and bodily control. Social Science and Medicine 66:1228-1239.

Barr PJ, Scholl I, Bravo P, Faber MJ, Elwyn G, McAllister M (2015). Assessment of Patient Empowerment - A Systematic Review of Measures. PLoS ONE 10(5):e0126553.

Bliuc A, Best D, Iqbal M, Upton K (2017). Building addiction recovery capital through online participation in a recovery community. Social Science and Medicine 193:110-117.

Castro EM, Regenmortel TV, Vanhaecht K, Sermeus W, Van Hecke A. (2016). Patient empowerment, patient participation and patientcenteredness in hospital care: A concept analysis based on a literature review. Patient Education and Counseling 99:1923-1939.
Centola D, van de Rijt A (2015). Choosing your network: social preferences in an online health community. Social Science and Medicine 125:19-31.

de la Peña A, Quintanilla C (2015). Share, like and achieve: the power of Facebook to reach health-related goals. International Journal of Consumer Studies 39:495-505.

Daruwalla Z, Thakkar V, Aggarwal M, Kiasatdolatabadi A, Guergachi A, Keshavjee K (2019). Patient Empowerment: The Role of Technology. In. Lau F. et al (eds), Improving Usability, Safety and Patient Outcomes with Health Information Technology. Amsterdam, Berlin, Washington: IOS Press, pp. 70-74 https://pdfs.semanticscholar.org/8141/c5c3f62e1346cc200fbaf429d9 88b7130e04.pdf (Accessed 31 January 2020)

De Luca V, Birov S, Beyhan O, Robinson S, Sanchez-Nanclares G, Acuña MD, Fernandes A, Hammerschmidt R, Annuzzi G, laccarino G, Illario M (2019). European Specifications for Value-based PreCommercial Procurement of Innovative ICT for Empowerment and Self-management of Diabetes Mellitus Patients. In. Proceedings of the 5th International Conference on Information and Communication Technologies for Ageing Well and e-Health (ICT4AWE 2019) pp. 1927.

https://pdfs.semanticscholar.org/827b/813e160c4952fba819b3ed5b0 c2afb8d84a3.pdf (accessed 31 January 2020)

Dickins M, Browning C, Feldman S, Thomas S (2016). Social inclusion and the Fatosphere: the role of an online weblogging community in fostering social inclusion. Sociology of Health and IIIness 38(5):797811.

Erfani SS, Abedin B, Blount Y (2016). The Effect of Social Network Site Use on the Psychological Well-Being of Cancer Patients. Journal of the Association for Information Science and Technology 68(5):13081322.

Fergie G, Hunt K, Hilton S (2016). Social media as a space for support: Young adults' perspective on producing and consuming usergenerated content about diabetes and mental health. Social Science and Medicine 170:46-54.

Foster D (2016). 'Keep complaining til someone listens': exchange of tacit healthcare knowledge in online illness communities. Social Science and Medicine 166:25-32.

Geelen E, van Vliet H, de Hoogh P, Horstman K (2016). Taming the fear of voice: Dilemmas in maintaining a high vaccination rate in the Netherlands. Social Science and Medicine 153:12-19.

Griffiths F, Cave J, Boardman F, Ren J, Pawlikowska T, Ball R, Clarke A, Cohen A (2012). Social networks - The future for health care delivery. Social Science and Medicine 75:2233-2241.

Ippolito A, Smaldone F, Ruberto M (2019). Exploring patient empowerment. The link between satisfying physician relationship and patient involvement. The TQM Journal 32(1):92-109.

Jaana M, Sherrard H, Paré G (2019). A prospective evaluation of telemonitoring use by seniors with chronic heart failure: Adoption, self-care, and empowerment. Health Informatics Journal 25(4):18001814.

Karni L, Memedi M, Klein GO (2019). Targeting Patient Empowerment via ICT interventions: An ICT-specific Analytical Framework, Twentyfifth Americas Conference on Information Systems, Cancun.

Kondylakisa $H$, Bucurb A, Cricoc C, Dong F, Graf N, Hoffman S, Koumakis L, Manenti A, Marias K, Mazzocco K, Pravettoni G (2020). Patient empowerment for cancer patients through a novel ICT infrastructure. Journal of Biomedical Informatics 101:103342.

Koteyko N, Hunt D, Gunter B (2015). Expectations in the field of the internet and health: an analysis of claims about social networking sites in clinical literature. Sociology of Health and IIIness 37(3):468484.

Kübler-Ross E (1969). On death and dying. New York, NY: Macmillan Publishing.

Lupton D (2013). The digitally engaged patient: Self-monitoring and self-care in the digital health era. Social Theory and Health 11(3):256-270.

Lupton D (2014a). Beyond Techno-Utopia: Critical Approaches to Digital Health Technologies. Societies 4:706-711.

Lupton D (2014b). Apps as artefact: towards a critical perspective on mobile health and medical apps. Societies 4(4):606-622.

Lupton D (2015). Quantified sex: a critical analysis of sexual and 
reproductive self-tracking using apps. Culture, Health and Sexuality $17(4): 440-453$

Lupton D, Jutel A (2015). 'It's like having a physician in your pocket!' A critical analysis of self-diagnosis smartphone apps. Social Science and Medicine 133:128-135.

Lupton D, Michael M (2017). Depends on who's got the data: public understanding of personal digital dataveillance. Surveillance and Society 15(2):254-268.

Maslen S, Lupton D (2019). Keeping It Real. Women's Enactments of Lay Health Knowledges and Expertise on Facebook. Sociology of Health and IIIness 41(8):1637-1651.

Nielsen MK, Johannessen H (2019). Patient empowerment and involvement in telemedicine. Journal of Nursing Education and Practice 9(8):54-58.

O'Neill B, Ziebland S, Valderas J, Lupiáñez-Villanueva F (2014). Usergenerated online health content: a survey of internet users in the United Kingdom. Journal of Medical Internet Research 16(4):e118.

Pempek TA, Yermolayeva YA, Calvert SL (2009). College students' social networking experiences on Facebook. Journal of Applied Developmental Psychology 30:227-238.

Petrakaki D, Hilberg E, Waring J (2018). Between empowerment and self-discipline: Governing patients' conduct through technological self-care. Social Science and Medicine 213:146-153.

Pols J. (2012). Care at a distance: on the closeness of technology. (Care \& Welfare). Amsterdam: Amsterdam University Press

Rijken M, Jones M, Heijmans M, Dixon A (2008). Supporting selfmanagement. In. Nolte E, McKee M (Eds.), Caring for people with chronic conditions: a health system perspective. Berkshire: Open University Press, pp. 116-142.

Roberts KJ (1999). Patient empowerment in the United States: a critical commentary. Health Expectations 2:82-92.

Saffran K, Fitzsimmons-Craft EE, Wilfley DE, Barr Taylor C, Trockel M (2016). Facebook Usage Among Those Who Have Received Treatment for an Eating Disorder in a Group Setting. International Journal of Eating Disorders 49(8):764-777.

Sharon T (2017). Self-Tracking for Health and the Quantified Self: ReArticulating Autonomy, Solidarity, and Authenticity in an Age of Personalized Healthcare. Philosophy and Technology 30(1):93-121.

Shultz PJ, Nakamoto K (2013). Patient behavior and the benefits of artificial intelligence: The perils of "dangerous" literacy and illusory patient empowerment. Patient Education and Counseling 92:223228.

Statista (2020). Facebook: number of monthly active users worldwide 2008-2019, https://www.statista.com/statistics/264810/number-ofmonthly-active-facebook-users-worldwide/ (Accessed 11/02/2020).

Swan M (2009). Emerging patient-driven health care models: an examination of health social network, consumer personalized medicine and quantified self-tracking. International Journal of Environmental Research and Public Health 6:492-525.

Swan M (2013). The Quantified-Self: fundamental disruption in big data science and biological discovery. Big Data 1(2):85-99.

Syn SY, Kim SU (2013). The impact of source credibility on young adults' health information activities on Facebook: preliminary findings. Retrieved https://onlinelibrary.wiley.com/doi/epdf/10.1002/meet.14505001122

Tan SSL, Goonawardene N (2017). Internet health information seeking and the patient-physician relationship: a systematic review. Journal of Medical Internet Research 19(1):e9.

Tomeny TS, Vargo CJ, El-Toukhy S (2017). Geographic and demographic correlates of autism-related anti-vaccine beliefs on Twitter, 2009-15. Social Science and Medicine 191:168-175.

Tonsaker T, Bartlett G, Trpkov C (2014). Health information on the internet. Gold mine or minefield? Canadian Family Physician 60:407408.
Topol E (2015). The patient will see you now. The future of medicine is in your hands. New York: Basic Books.

Twaddle A (1968). Influence and illness: Definitions and definers of illness behavior among older males in Providence, Rhode Island. $\mathrm{PhD}$ dissertation. Brown University, Providence, RI.

van der Eijk M, Faber MJ, Aarts JWM, Kremer JA, Munneke M, Bloem BR (2013). Using online Health Communities to Deliver PatientCentered Care to People with Chronic Conditions. Journal of Medical Internet Research 15(6):e115.

Van Dijck J (2014). Datafication, dataism and dataveillance: Big Data between scientific paradigm and ideology. Surveillance and Society 12(2):197-208.

van Uden-Kraan CF, Drossaert CHC, Taal E, Shaw BR, Seydel ER, van de Laar MAFJ (2008). Empowering Processes and Outcomes of Participation in Online Support Groups for Patients with Breast Cancer, Arthritis, or Fibromyalgia. Qualitative Health Research 18(3):405-417.

Verduyn P, Ybarra O, Résibois M, Jonides J, Kross E (2017). Do Social Network Sites Enhance or Undermine Subjective Well-Being? A Critical Review. Social Issues and Policy Review 11(1):274-302.

Willis E, Royne MB (2017). Online health communities and chronic disease self-management. Health Communication, 32(3): 269-278.

Willis E (2016). Patients' self-efficacy within online health communities: facilitating chronic disease self-management behaviors through peer education. Health Communication 31(3):299-307.

Wray S (2004). What constitutes agency and empowerment for women in later life? The Sociological Review 52(1):22-38.

Ybarra M, Suman M (2008). Reasons, assessments and actions taken: sex and age differences in uses of internet health information. Health Education Research 23(3):512-521. 